\title{
Effective Factors in Urinary Tract Infection Prevention among Children: Application of Health Belief Model
}

\author{
Mina-Sadat Hashemiparast ${ }^{1}$, Davoud Shojaeizadeh ${ }^{1}$, Kamal Aezam $^{2}$, Azar Tol ${ }^{1}$ \\ ${ }^{1}$ Department of Health Promotion and Education, School of Public Health, Tehran University of Medical \\ Sciences, Tehran, Iran \\ ${ }^{2}$ Department of Epidemiology and Biostatistics, School of Public Health, Tehran University of Medical Sciences, \\ Tehran, Iran \\ Email: Mina.Hashemi26@yahoo.com, ${ }^{*}$ shojae5@yahoo.com, kazam@tums.ac.ir, Tol.azar@yahoo.com
}

Received 7 January 2015; accepted 13 February 2015; published 16 February 2015

Copyright (C) 2015 by authors and Scientific Research Publishing Inc.

This work is licensed under the Creative Commons Attribution International License (CC BY). http://creativecommons.org/licenses/by/4.0/

(c) $\underset{\mathrm{EY}}{\mathrm{O}}$ Open Access

\begin{abstract}
Urinary Tract Infection (UTI) is one of the most common bacterial infections among children using preventive manipulations, especially among children less than 6 years old. This study aimed at exploring factors which could affect urinary tract infection prevention among children. A descriptive analytical study was conducted on 70 mothers who had children less than 6 years old in 2013. Multistage cluster sampling method was utilized in which each kindergarten was considered as a cluster and data were collected by a researcher-made questionnaire designed based on Health Belief Model (HBM). Validity and reliability of questionnaire were confirmed by a pilot study. ANOVA and Pearson Correlation Coefficient were conducted using SPSS, version 18. The mean and standard deviation of knowledge and practice were $6.96 \pm 2.14$ and $15.47 \pm 1.54$ respectively. Means and standard deviation of Health Belief Model constructs (perceived susceptibility, perceived severity, perceived benefits, perceived barriers and self-efficacy) were 17.64 $\pm 2.50,22.02 \pm 2.55,20.90 \pm$ $2.38,27.56 \pm 5.20$ and $21.49 \pm 3.18$ respectively. More participants were in the moderate levels of knowledge $(74.3 \%)$ and practice $(45.7 \%)$. These findings revealed a significant relation between practice and perceived susceptibility $(p=0.02)$, perceived barriers $(p=0.001)$, self-efficacy $(p=$ $0.014)$ and cues to action $(p=0.016)$. Based on the current study, the intervention based on Health Belief Model can be useful to improve preventive behaviors of Urinary Tract Infection.
\end{abstract}

\section{Keywords}

Urinary Tract Infection, Health Belief Model, Behavior, Prevention

\footnotetext{
${ }^{*}$ Corresponding author.
}

How to cite this paper: Hashemiparast, M.-S., Shojaeizadeh, D., Aezam, K. and Tol, A. (2015) Effective Factors in Urinary Tract Infection Prevention among Children: Application of Health Belief Model. Open Journal of Preventive Medicine, 5, 7277. http://dx.doi.org/10.4236/ojpm.2015.52008 


\section{Introduction}

Urinary Tract Infection (UTI) is one of the most common bacterial infections among children [1]. The studies reveal that the prevalence of infection depends largely on age and gender of children [2]. Approximately, $2 \%$ of boys and $8 \%$ of girls are affected at the age of 7 years old [3]. In terms of epidemiological studies, it is estimated that about 150 million general patients are annually diagnosed with urinary tract infection and that a minimum amount of $\$ 6$ million is the cost expense for care [4]. Although advanced methods of diagnosis and therapy exist, gripped persons are infected with long-term complications of urinary tract infection, such as "renal scaring which can subsequently lead to hypertension, uremia, complications during pregnancy (preeclampsia) [5] and even chronic kidney disease" [6] [7]. Another problem in Urinary Tract Infections (UTIs) is bacterial resistance and the most important risk factor for development of this problem is the previous exposure to microbial agents [8] [9]. In addition, in $25 \%$ - $40 \%$ of children with urinary tract infections, there are vesico-ureteral reflux (VUR), which has a high impact on health-care costs and health status of affected children [10], while this problem is preventable in many cases. Also, an appropriate preventive health behavior can develop personal immune against the disease. The available evidence shows the important role of timely diagnosis and treatment in childhood UTIs to prevent long-term outcomes of the infection [11]. For early diagnosis and treatment of childhood UTIs, high level of knowledge about the disease and its warning signs are important among parents [12].

Effective health education interventions are largely designed based on theories and models [13]. Theories can be implemented successfully in health behavior change and maintenance [14]. From several models utilized for individual health, education program designing is Health Belief Model (HBM) [11]. HBM explains the failure of people to accept prevention of disease or screening tests to discover asymptomatic disease [15]. According to this model, possibility of acquiring the preventive behaviors in each person is affected by his perceptions about the condition: perceived susceptibility (beliefs about the likelihood of getting a disease or condition); perceived severity (feelings about the seriousness of contracting an illness or of leaving it untreated include evaluations of both medical and clinical consequences and possible social consequences); perceived benefits (personal understanding of the profit resulting from the adoption of preventive behavior); perceived barriers (the potential negative aspects of a particular health action); cues to action (the stimulus accelerating decision making and cause feel the need to perform the behavior); self-efficacy (the conviction that one can successfully execute the behavior required to produce the outcomes) [16]. Because of high prevalence of urinary tract infection in children, the prominent importance of knowledge and preventive behavior on prevention and timely treatment of UTI is the corner stone of activities which are exerted to prevent the disease among children. Therefore, this study was intended to identify determinants of preventative behaviors of urinary tract infection based on Health Belief Model among mothers with children less than 6 years old.

\section{Methods}

This study was a descriptive analytical study and foreground for future interventional study and has been done among mothers with children less than 6 years old in kinder garden in 2013. The required sample size calculated based on the sample volume determination formula, mean of perceptions and the preventive behaviors of UTI. As such approximately 70 mothers who had children less than 6 years old selected and entered into the study. To select a representative sample, a multistage cluster sampling was applied. Among the total kinder gardens of sixth district in Tehran, three kinder gardens were selected as a cluster. Then children in these three kinder gardens were included in our study consecutively. Data collection tool was a questionnaire designed by researcher based on the constructs of HBM. For the purpose of the content validity, the questionnaire was tested by a group of health education and promotion experts. To assess the internal consistency of the instrument Cronbach's $\alpha$ Coefficient was calculated. Cronbach's $\alpha$ of 0.70 and above was considered acceptable [17]. In this study, Cronbach's $\alpha$ was 0.77 . Reliability was evaluated using test-retest method. Twenty mothers completed the questionnaire twice with time intervals of two weeks.

The questionnaire was designed in three parts: The first section includes 11 items measure demographic characteristics of mothers such as age, marital status, employment and educational level, second part consists of six items to measure knowledge about Urinary Tract Infection (Cause of disease, signs and symptoms, complications, prevention methods) and third part consists of four items to assess the performance of maternal behavior which guided by HBM. Questions related to HBM constructs were based on five points Likert scale that ranges from strongly disagree with score 1 to strongly agree with score 5 . This score was then summed, with increasing 
scores reflecting an increasing degree of performance maternal behavior. Accordingly, for perceived susceptibility, perceived severity, perceived benefits and perceived self-efficacy the maximum scores were 25 and the minimum 5 with a total of 5 items for each. Similarly for perceived barriers and cues to action the maximum scores were 35 and 15 respectively and the minimum 7 and 3 based on their items.

The questionnaires were scored as follow: in knowledge section, scores were calculated from 12 score $(1=$ correct response, $0=$ false response). In this section, according to mean \pm standard deviation, the scores from 0 to 4 consider as weak knowledge, 5 to 9 as moderate knowledge and above 10 as good knowledge. Twenty nine (29) attitude items were designed and the responses were recorded based on five point Lickert scale (1 to 5 score). The highest score considered for completely agreement tendency and the lowest for quietly opponent. In perceived susceptibility section, the scores below 18 consider as weak, 19 to 21 as moderate and above 22 as good susceptibility. Also, scores between 5 to 19 considered as weak severity, 20 to 24 considered as moderate, then 25 and above considered as good severity. Similarly, scores from 5 to 18 , scores from 19 to 23 and above 24 considered as weak benefit, moderate benefit and good benefit, respectively. For barriers, scores from 7 to 24 considered as weak barriers, 25 to 31 moderate barriers and 32 to 35 as strong barriers. Finally, scores from 5 to 18,19 to 23 and above 24 considered as weak, moderate and good perceived self-efficacy respectively. In the section of cues to action, we had 2 types of question (one question, multiple-choice of 14) which people permitted select more than one choice, scores varied from 0 to 14 and 3 items in the internal cues to action. The scores below 12 consider as weak, 13 to 15 as moderate and above 15 as good respectively. All of participants completed the questionnaires before and after educational intervention. The data were analyzed by SPSS version 18 and STATA soft-ware. For statistical testing, ANOVA and Pearson Correlation Coefficient were used. $p$-value $<$ 0.05 was considered as statistically significant.

\section{Ethical Considerations}

The study received relevant approvals from Ethics Committee of Tehran University of Medical Sciences. Written informed consent was filled by all participants and assured their responses would be analyzed confidentially.

\section{Results}

In this study, $14.3 \%$ of mothers were diploma and lower holder; the remains had college degrees. Additional sample characteristics are described in Table 1. The mean and standard deviation of knowledge and function were $6.96 \pm 2.14$ and $15.47 \pm 1.54$ respectively. $74.3 \%$ of mothers were at middle level score of knowledge and about $11.4 \%$ were in desired level. The means and standard deviation of mothers perceived susceptibility, perceived severity, perceived benefits, perceived barriers, cues to action and self-efficacy were $17.64 \pm 2.50,22.02$ $\pm 2.55,20.90 \pm 2.38,27.56 \pm 5.20,13.31 \pm 2.12$ and $21.49 \pm 3.18$ respectively. The most important sources of information about prevention of UTIs were mass media such as Television (47.1\%), books (58.6\%), publications and magazine (41.4\%). Posters were the lowest source for information (4.3\%). One way ANOVA test was done to assess the relation between level of mother's education, job status and preventive behaviors of UTIs and there was no significant relation $(p>0.05)$. Pearson Correlation Coefficient was used to assess the relation between preventive behaviors of UTIs and constructs of HBM. The result was showed a significant correlation between preventive behavior and HBM domains. The mean behavior score had strong correlation with perceived barriers $(r=0.45)$ and weak with perceived susceptibility $(r=0.24)$. However, there was no any meaningful relation between knowledge and function. Also, Pearson Correlation test showed a significant inverse correlation between maternal age and knowledge $(r=-0.24, p=0.045)$. Pearson Correlation was employed to assess the relation between constructs of HBM and the results were showed a significant relation between some of constructs $(p<0.05)$ (Table 2).

\section{Discussion}

This study found, majority of mothers were in the average level of knowledge and perceptions about childhood UTIs. The most of them did not have accurate information about causes of disease, signs and symptoms, complications, predisposing factors and methods of prevention. A study by Baghiani et al. [18] showed most of the mothers were in the middle level of knowledge score which was consistent with our findings. In terms of preventive behaviors of UTIs, i.e. washing the child correctly, changing diapers after voiding and defecation and 
Table 1. Demographic characteristics of the participants (mean \pm SD, No, $\%, n=70$ ).

\begin{tabular}{lcc}
\hline & Age (yrs) & $\mathbf{3 5 . 5 4} \pm \mathbf{4 . 3 9}$ \\
\hline Job & No. $\mathbf{( \% )}$ \\
Household & $11(15.7)$ \\
Employed & $59(84.3)$ \\
Education level & \\
$\quad \begin{array}{l}\text { Diploma } \\
\text { College degrees }\end{array}$ & $10(14.3)$ \\
The number of children & $60(85.7)$ \\
Only one child & \\
Two children & $60(85.7)$ \\
Type of care & $10(14.3)$ \\
Home & $18(25.7)$ \\
Kindergarten & $52(74.3)$ \\
History of infection & \\
Yes & $10(14.3)$ \\
No & $60(85.7)$ \\
\hline
\end{tabular}

Table 2. The relation between Health Belief Model constructs knowledge and Behavior.

\begin{tabular}{|c|c|c|c|c|c|c|c|c|c|}
\hline & & $\begin{array}{c}\text { Perceived } \\
\text { Susceptibility }\end{array}$ & $\begin{array}{c}\text { Perceived } \\
\text { Severity }\end{array}$ & $\begin{array}{c}\text { Perceived } \\
\text { Benefits }\end{array}$ & $\begin{array}{c}\text { Perceived } \\
\text { Barriers }\end{array}$ & Self-Efficacy & Cues to Action & knowledge & Behavior \\
\hline \multirow[t]{2}{*}{ Susceptibility } & $r$ & - & & & & & & & \\
\hline & $p$ & & & & & & & & \\
\hline \multirow[t]{2}{*}{ Severity } & $r$ & 0.131 & - & & & & & & \\
\hline & $p$ & 0.279 & & & & & & & \\
\hline \multirow[t]{2}{*}{ Benefits } & $r$ & $-0.021^{*}$ & 0.498 & - & & & & & \\
\hline & $p$ & 0.865 & $0.001{ }^{* *}$ & & & & & & \\
\hline \multirow[t]{2}{*}{ Barriers } & $r$ & $-0.006 *$ & 0.155 & 0.081 & - & & & & \\
\hline & $p$ & 0.960 & 0.200 & 0.507 & & & & & \\
\hline \multirow[t]{2}{*}{ Self-efficacy } & $r$ & 0.044 & 0.295 & 0.366 & 0.324 & - & & & \\
\hline & $p$ & 0.717 & $\mathbf{0 . 0 1 3}^{*}$ & $0.002^{*}$ & $0.006^{*}$ & & & & \\
\hline \multirow[t]{2}{*}{ Cues to action } & $r$ & 0.294 & 0.033 & 0.003 & 0.222 & 0.063 & - & & \\
\hline & $p$ & $0.014^{*}$ & 0.786 & 0.977 & 0.065 & 0.064 & & & \\
\hline \multirow[t]{2}{*}{ Knowledge } & $r$ & 0.109 & -0.013 & -0.004 & -0.043 & 0.009 & 0.041 & - & \\
\hline & $p$ & 0.370 & 0.915 & 0.976 & 0.721 & 0.938 & 0.735 & & \\
\hline \multirow[t]{2}{*}{ Behavior } & $r$ & 0.249 & 0.059 & 0.008 & 0.455 & 0.298 & 0.290 & -0.034 & - \\
\hline & $p$ & $0.041^{*}$ & 0.635 & 0.949 & $0.001^{* *}$ & $0.014^{*}$ & $0.016^{*}$ & 0.872 & \\
\hline
\end{tabular}

${ }^{*}$ Significant at $<0.05 ;{ }^{* *}$ Significant at $<0.001$.

visiting the GP if there are any signs of infection the most of participants were in middle level of behavior. In this study, the mean score HBM constructs were indicates moderate level. However, in other similar study reported by Baghiani et al. (2013) the most participants were scored high level [18]. According to previous studies perceived susceptibility and perceived severity (perceived threat) had a strong cognitive component that depends largely on knowledge of individuals [19]. The influence of knowledge on perceived susceptibility and perceived severity was similarly indicated in our finding. This implies, perceived susceptibility and perceived severity can be adjusted through increasing mother's knowledge about childhood UTIs. Hence, planning an appropriate in- 
terventions based on HBM constructs could be useful. Also, other factors such as sociodemographic factors come into play here. Based on our results, the age of mothers had significant inverse relation with the mean score of mothers' knowledge, so any intervention should be consider the characteristics of the target population. The assessment of relation between the preventive behaviors of childhood UTI and some constructs of HBM (cues to action, perceived self-efficacy, perceived susceptibility and barriers) were showed a significant relation. Previous studies explain the important role of perceived barriers in prediction of behaviors [19]. The results revealed mothers were adopted the preventive behaviors of UTI for their children while overcoming barriers, i.e. changing diapers after any voiding and defecation. So, reducing the psychological and tangible barriers could be effective in preventive behaviors. In studies were applied HBM for prevention of UTI [18], cardiovascular diseases [20], addiction and drug abuse [21] revealed meaningful correlation between function and perceived susceptibility, perceived severity and self-efficacy has been found. Also, there was a significant correlation between self-efficacy and cues to action, perceived barriers and benefits. Furthermore, these studies showed the strong relation between perceived benefits and adoption of preventive behaviors, which were similar to our result. In this study, there was no any meaningful correlation between knowledge and behavior that was similar to study by Niksadat et al. (2013) on prevention of self-medication [22]. Our study demonstrates media such as Television, books, publications and magazines were the most important sources for obtaining information about prevention of UTIs. Hence, these are more acceptable among participants and could be used successfully as educational resources. Our project has some limitations because of time and budget constrain. The sample size collected for the study was only 70 mothers who have children less than 6 years of age because, the time and budget allocated for the study was too small. Because of this small sample size and other assumption of regression, regression test to assess the relations between each HBM domains and preventive behaviors, and the effect of each HBM on each others were not conducted. Therefore, in future studies to assess the relation between HBM domains and preventive behaviors of UTI and the effect of each HBM domains on each other to determine preventive behavior by regression which is an appropriate and powerful statistical test to estimate reliable effect on performing preventive behavior enrolling of sufficient sample size based on recommended formula and number of independent variable are compulsory. Also, due to limitation of similar studies conducted so far, this study fail to compare its findings to discuss effectively.

\section{Conclusion}

The study reviled that perceived susceptibility and barriers, cues to action and self-efficacy were the effective factors in preventive behaviors of UTI that confirmed the assumption of HBM which stated preventive behaviors based on the individuals' beliefs. Hence, we would like to recommend theory-based educational intervention approaches to enhance preventive behaviors of UTI among mothers to prevent children from UTI and its complications.

\section{Acknowledgements}

This study is a part of MS thesis in health education and promotion major. Authors would like to acknowledge all participants who took part in this study and all staff members of Health Education and Promotion Department, School of Public Health Tehran University of Medical Sciences for their unreserved administrative support during this study.

\section{Conflict of Interest}

None.

\section{References}

[1] Oh, M., Cheon, J., Kang, S., et al. (2010) Predictive Factors for Acute Renal Cortical Scintigraphic Lesion and Ultimate Scar Formation in Children with First Febrile Urinary Tract Infection. The Journal of Urology, 183, 1146-1150. http://dx.doi.org/10.1016/j.juro.2009.11.051

[2] Chen, J.J., Mao, W., Homayoonandgeorge, K. and Steinhardt, F. (2004) A Multivariate Analysis of Dysfunctional Elimination Syndrome, and Its Relationships with Gender, Urinary Tract Infection and Vesicoureteral Reflux in Children. The Journal of Urology, 171, 1907-1910. http://dx.doi.org/10.1097/01.ju.0000120288.82950.a2 
[3] Craig, J., Simpson, J., Williams, G., et al. (2009) Antibiotic Prophylaxis and Recurrent Urinary Tract Infection in Children. The New England Journal of Medicine, 361, 1748-1759. http://dx.doi.org/10.1056/NEJMoa0902295

[4] Tanagho, E.A. and McAninch, J.W. (2008) Smith's General Urology. McGraw-Hill Medical, New York.

[5] Montini, G., Tullus, K. and Hewitt, L. (2011) Febrile Urinary Tract Infections in Children. The New England Journal of Medicine, 365, 239-250. http://dx.doi.org/10.1056/NEJMra1007755

[6] Harmsen, M., Adang, E., Wolters, R., et al. (2009) Management of Childhood Urinary Tract Infections: An Economic Modeling Study. Value in Health, 12, 466-472. http://dx.doi.org/10.1111/j.1524-4733.2008.00477.x

[7] Bremberg, S.G. and Edström, S. (2001) Outcome Assessment of Routine Medical Practice in Handling Child Urinary tract Infections: Estimation of Renal Scar Incidence. Ambulatory Child Health, 7, 149-155.

[8] Paschke, A.A., Zaoutis, T., Conway, P., et al. (2010) Previous Antimicrobial Exposure Is Associated with Drug-Resistant Urinary Tract Infections in Children. Pediatrics, 125, 664-672. http://dx.doi.org/10.1542/peds.2009-1527

[9] Butler, C.C., Dunstan, F., Heginbothom, M., et al. (2007) Containing Antibiotic Resistance: Decreased Antibiotic-Resistant Coliform Urinary Tract Infections with Reduction in Antibiotic Prescribing by General Practices. British Journal of General Practice, 57, 785-792.

[10] Ghanesherbaf, F., Kharazme, A., Gharaeigomei, R., et al. (2011) Related Factors with Permanent Scar in Children with Urinary Tract Infections. Journal of North Khorasan University of Medical Sciences, 3, 57-67.

[11] Harmsen, M., Wensing, M., Wouden, J. and Grol, R. (2007) Parents' Awareness of and Knowledge about Young Children's Urinary Tract Infections. Patient Education and Counseling, 66, 250-255. http://dx.doi.org/10.1016/j.pec.2006.12.009

[12] Owen, D., Vidal-Alaball, J., Mansour, M., Bordeaux, K., Jones, K.V. and Edwards, A. (2003) Parent's Opinions on the Diagnosis of Children under 2 Years of Age with Urinary Tract Infection. Family Practice, 20, 531-537. http://dx.doi.org/10.1093/fampra/cmg507

[13] Hazavehei, S.M., Sharifirad, G. and Mohabi, S. (2007) The Effect of Educational Program Based on Health Belief Model on Diabetic Foot Care. International Journal of Diabetes in Developing Countries, 27, 18. http://dx.doi.org/10.4103/0973-3930.34753

[14] Patrick, H. and Williams, G.C. (2012) Self-Determination Theory: Its Application to Health Behavior and Complementarity with Motivational Interviewing. International Journal of Behavioral Nutrition and Physical Activity, 9, 18. http://dx.doi.org/10.1186/1479-5868-9-18

[15] Jones, P.K., Jones, S.L. and Katz, J. (1990) A Randomized Trial to Improve Compliance in Urinary Tract Infection Patients in the Emergency Department. Annals of Emergency Medicine, 19, 16-20. http://dx.doi.org/10.1016/S0196-0644(05)82133-X

[16] Glanz, K., Rimer, B. and Viswanath, K. (2008) Health Behavior and Health Education: Theory, Research, and Practice. John Wiley \& Sons, Hoboken.

[17] Cronbach, L.J. (1951) Coefficient Alpha and the Internal Structure of Tests. Psychometrika, 16, 297-334. http://dx.doi.org/10.1007/BF02310555

[18] Baghiani, M.M., Shojaezade, D., Mohamadlo, A., Fallahzadeh, H. and Ranjbary, M. (2013) Evaluation of Preventive Behaviors of UTI Based on Health Belief Model in Mothers with Girls Younger than 6 Years Old. Journal of TolooE-Behdasht, 12, 78-88.

[19] Saffari, M. and Shojaezade, D. (2009) Health Education and Promotion (Theories, Models \& Methods). Sobhan Publication, Tehran, 55-57.

[20] Mehri, A. and Mohaghegh, M. (2010) Utilizing the Health Belief Model to Predict Preventive Behaviors for Heart Diseases in the Students of Islamic Azad University of Sabzevar. Journal of Toloo-E-Behdasht, 9, 21-33.

[21] Masodi, D., Baghiani, M.H., Sharifirad, G. and Falahzade, H. (2012) Evaluation of Preventive Behaviors of Addiction Based on Health Belief Model (HBM) among Male High School Students in Boroujen, Iran. Health System Research, 8, 237-246.

[22] Niksadat, N., Solhi, M., Shojaezade, D. and Gohari, M. (2013) Effective Factors in Prevention of Self-Medication Based on Health Belief Model in Women Referring to the Health Homes in Tehran's 3rd District, 2012. HealthMed, 7 , 174. 
Scientific Research Publishing (SCIRP) is one of the largest Open Access journal publishers. It is currently publishing more than 200 open access, online, peer-reviewed journals covering a wide range of academic disciplines. SCIRP serves the worldwide academic communities and contributes to the progress and application of science with its publication.

Other selected journals from SCIRP are listed as below. Submit your manuscript to us via either submit@scirp.org or Online Submission Portal.
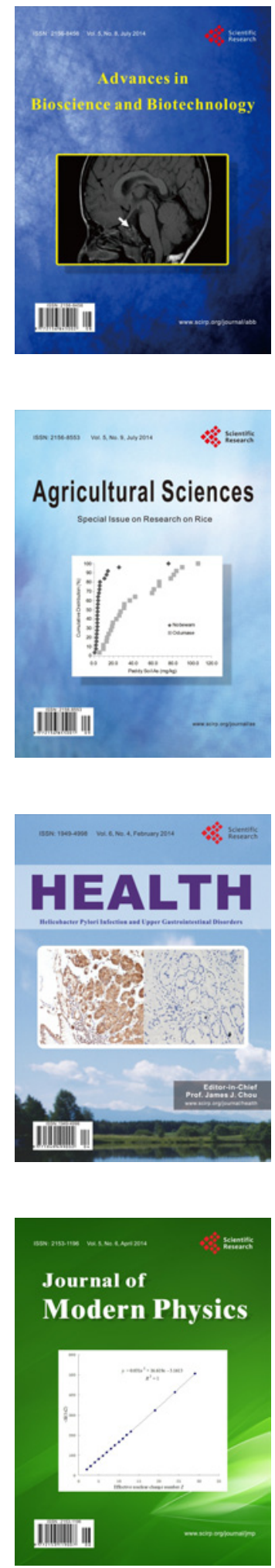
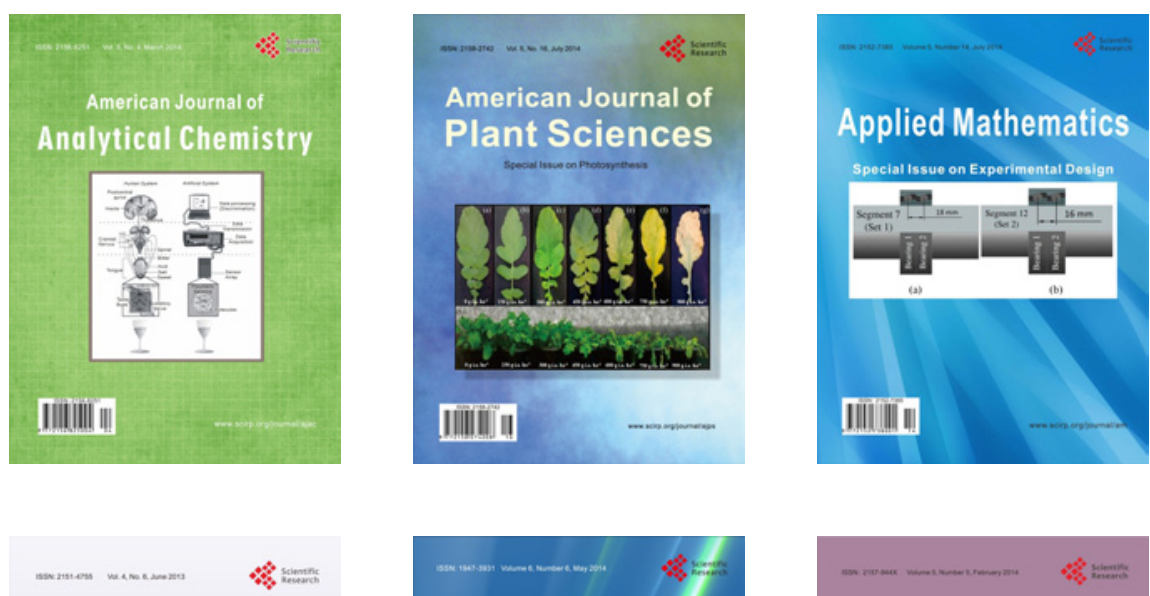

Creative Education
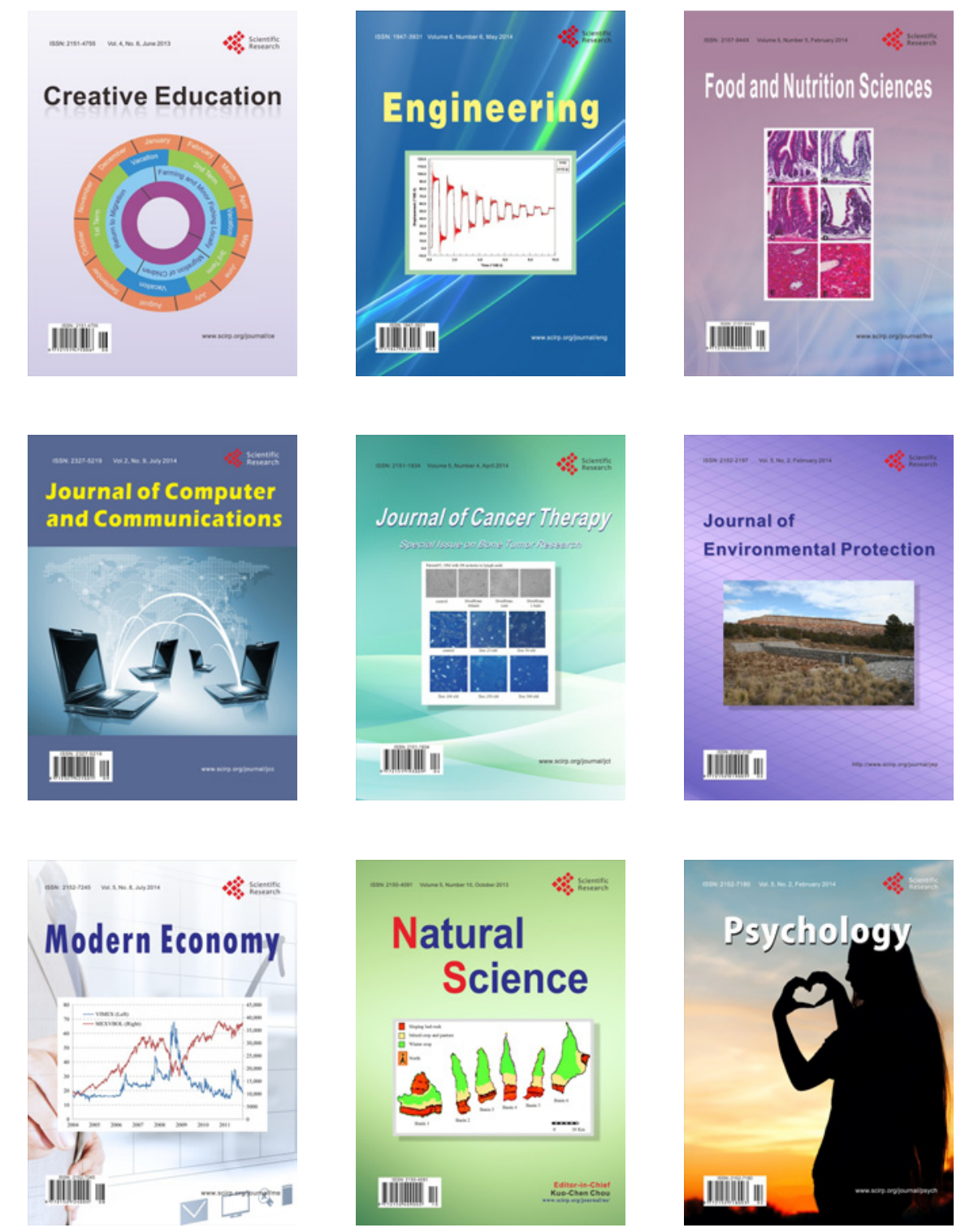